\title{
JEKK
}

Jurnal Epidemiologi Kesehatan Komunitas

$4(1), 2019,45-54$

\section{Faktor-Faktor yang Berpengaruh terhadap Kualitas Hidup Penyelam Tradisional Penderita Penyakit Dekompresi}

\author{
Sri Rahayu Widyastuti", Soeharyo Hadisaputro ${ }^{* *}$, Munasik ${ }^{* * * *}$ \\ "Kesehatan Pelabuhan Kelas II Semarang, ${ }^{* *}$ Fakultas Kesehatan Masyarakat Undip, ${ }^{* * *}$ Fakultas \\ Perikanan dan Ilmu Kelautan Undip
}

\begin{abstract}
Background: Decompression sickness is thought to have effect on health related quality of life (HRQL), however, not yet known factors that affect quality of life on traditional divers with decompression sickness.

Methods: This research was a mix methode research with case-control study design which strengthened by FGD. The participants were 66 volunteer, consist of 33 cases dan 33 controls. The data obtained from the study were analyzed using bivariate and multivariate analysis.

Results: Variables that had been proven to affect poor quality of life were history of hypertension comorbid $(\mathrm{p}=0.010 ; \mathrm{OR}=65.476 ; 95 \% \mathrm{CI}=2.735-1,568)$, diving depth $\geq 30$ meters $(\mathrm{p}=0.014 ; \mathrm{OR}=38.410 ; 95 \% \mathrm{CI}=2.114-698.028)$, history of loss of consciousness during diving $(\mathrm{p}=0.009 ; \mathrm{OR}=12.456,95 \% \mathrm{CI}=1.884-82.363)$, diving duration $\geq 2$ hours $(\mathrm{p}=0.021 ; \mathrm{OR}=9.860 ; 95 \% \mathrm{CI}=1.410-68.943)$, suffering from anemia $(\mathrm{p}=0.024 ; \mathrm{OR}=$ $8.837 ; 95 \% \mathrm{CI}=1.332-58.632)$, frequency of decompression sickness history $>1$ time $(\mathrm{p}=$ $0.020 ;$ OR $=8.834 ; 95 \% \mathrm{CI}=1.404-55.584)$.

Conclusion: Factors that had been proven to affect poor quality of life on traditional diver with decompression sickness were history of hypertension comorbid, diving depth $\geq 30$ meters, history of loss of consciousness during diving, diving duration $\geq 2$ hours, suffering from anemia, frequency of previous decompression sickness $>1$ time.
\end{abstract}

Keywords: Quality of life; Decompression sickness; HRQ; SF-36

*Penulis korespondensi : yayudya80@gmail.com 


\section{Pendahuluan}

Menyelam dan paparan hiperbarik dikaitkan dengan sejumlah penyakit akut dan luka yang dikenali dengan baik, termasuk penyakit dekompresi. ${ }^{1}$ Penyakit dekompresi disebabkan oleh gelembung dalam darah atau setelah pengurangan tekanan lingkungan (dekompresi). ${ }^{2}$ Darah dan jaringan penyelam menyerap nitrogen tambahan dari paru-paru pada kedalaman. Jika seseorang naik terlalu cepat, kelebihan gas ini akan terpisah dari larutan dan dari gelembung. Gelembung-gelembung menghasilkan efek mekanik dan biokimia yang mengarah ke kondisi yang dikenal sebagai penyakit dekompresi. ${ }^{3}$

Penyakit dekompresi adalah bahaya terkait pekerjaan, umumnya di kalangan penyelam nelayan dan disebabkan atau terkait dengan beberapa faktor. ${ }^{4}$ Penyelam melaporkan kerusakan saraf, penyakit kejiwaan, kelupaan atau kehilangan konsentrasi cenderung memiliki karir menyelam yang lebih lama dan menderita penyakit dekompresi. ${ }^{1,5}$ Penyelam tradisional kompresor dapat menderita penyakit dekompresi berupa kelumpuhan dan bahkan kematian. ${ }^{6}$ Di militer Amerika Serikat, Inggris, dan Kanada antara 1994 dan 1997, dilaporkan 190 kasus penyakit dekompresi. ${ }^{7}$ Insiden penyakit dekompresi pada penyelam gua Australia diperkirakan 2,8:10.000 $(0,028 \%) .{ }^{8}$ Insiden penyakit dekompresi pada penyelaman SCUBA Amerika adalah 1:2.900 penyelaman pada penyelam rekreasi, 1:280 penyelaman pada penyelam komersial, 1:3.770 penyelaman pada penyelam militer, 1:270 penyelaman pada penyelam olahraga (bangkai kapal), 1:1.000 penyelaman pada instruktur selam, 1:1.250 penyelaman pada penyelam olahraga (air dingin). ${ }^{9}$ Jumlah nelayan di Indonesia yang menunjukkan gejala penyakit dekompresi adalah $15,3 \% .^{10}$ Tahun 2006 di Pulau Bungin NTB, sebanyak $57,5 \%$ nelayan penyelam menunjukkan gejala penyakit dekompresi berupa nyeri persendian, sedangkan di Kepulauan Seribu, DKI Jakarta sebanyak $6,91 \%$ mengalami kelainan dekompresi. ${ }^{11}$ Insiden penyakit dekompresi di Karimunjawa adalah $56,1 \%$ pada penyelam nelayan. ${ }^{12}$

Kualitas hidup adalah persepsi individu terhadap posisi mereka dalam kehidupan, dalam konteks budaya dan sistem nilai dimana mereka tinggal dan hubungannya dengan tujuan, harapan, standar dan perhatian mereka. ${ }^{13}$ Penyakit dekompresi terjadi pada populasi kecil tetapi merupakan masalah internasional. Meskipun manifestasinya sering ringan, potensi cedera permanen ada pada kasus yang berat, terutama jika tidak dikenali atau tidak diobati secara memadai. ${ }^{2}$ Diver health score (DHS) ditemukan meningkat satu unit setiap kenaikan $1 \%$ dari risiko penyakit dekompresi. Peningkatan risiko penyakit dekompresi akan mengurangi status kesehatan penyelam sehingga kualitas hidup menurun. ${ }^{14}$ Kualitas hidup terkait kesehatan/health related quality of life (HRQL) berkurang pada sampel penelitian penyelam. Paparan menyelam di kedalaman maksimal dihubungkan dengan penurunan kualitas hidup terkait kesehatan pada skala nyeri tubuh, skala kesehatan secara umum, skala vitalitas, skala fungsi sosial, skala peran emosional, dan skala kesehatan mental. ${ }^{15}$

Di Karimunjawa, Jawa Tengah, masih memiliki penyelam tradisional. Berdasarkan data dari Puskesmas Karimunjawa, ada 140 kasus dan 14 kematian yang menyebabkan insiden hiperbarik (2003 hingga April 2017). Berdasarkan alasan ini, penelitian perlu dilakukan. Tujuan dari penelitian ini adalah untuk menjelaskan pengaruh faktor host dan environment terhadap kualitas hidup penyelam tradisional penderita penyakit dekompresi, yang dinilai dengan SF-36. 


\section{Metode}

Jenis penelitian adalah penelitian mix methode desain studi kasus kontrol yang diperkuat dengan FGD. Populasi penelitian dalam penelitian ini adalah penyelam tradisional dengan penyakit dekompresi di Karimunjawa, Jawa Tengah. Responden adalah 66 orang penyelam tradisional penderita penyakit dekompresi, yang diperoleh dengan teknik purposive sampling. Responden yang memiliki kualitas hidup buruk dimasukkan dalam kelompok kasus $(\mathrm{n}=33)$. Sedangkan responden yang memiliki kualitas hidup baik dimasukkan dalam kelompok kontrol $(n=33)$.

HRQL telah digunakan secara luas baik dalam penilaian kualitas hidup pada populasi umum dan pasien dengan penyakit kronis, atau untuk mengevaluasi efek terapeutik yang berbeda. The Medical Outcomes Study Short-Form General Health Survey (SF-36) digunakan secara luas dan divalidasi dalam penelitian medis. ${ }^{16}$ Kualitas hidup penyelam perlu diukur dengan menggunakan SF-36 untuk menyelidiki efek paparan menyelam pada HRQL saat ini.

HRQL diukur menggunakan kuesioner SF-36. Kualitas hidup buruk diukur dengan menggunakan kuesioner SF36 yang menunjukkan skor 0-50. Kualitas hidup baik diukur dengan menggunakan kuesioner SF-36 yang menunjukkan skor 51-100. ${ }^{17}$ Variabel dependen adalah kualitas hidup penyelam tradisional penderita penyakit dekompresi. Variabel independen adalah usia, obesitas, anemia, kebiasaan merokok, kebiasaan konsumsi alkohol, kedalaman menyelam, lama menyelam, menyelam berulang dalam hari yang sama, riwayat hilang kesadaran selama menyelam, frekuensi riwayat penyakit dekompresi, riwayat penyakit komorbid hipertensi, riwayat penyakit komorbid diabetes mellitus, riwayat penyakit komorbid jantung, dan riwayat penyakit komorbid sesak nafas.

Data primer dikumpulkan melalui wawancara tentang faktor host dan lingkungan dan skala kualitas hidup SF-36, yang dilanjutkan dengan FGD. Data sekunder diambil dari data rekam medis pasien penyakit dekompresi di Lembaga Kesehatan Kelautan TNI AL (LAKESLA) Drs. Med. R. Rijadi., Phys Surabaya dan Puskesmas Karimunjawa pada tahun 2010 hingga April 2017. Penelitian ini telah ditinjau dan disetujui oleh Komite Etik Penelitian Kesehatan (KEPK) Fakultas Kedokteran, Universitas Diponegoro dan Rumah Sakit dr. Kariadi Semarang dengan nomor ethical clearance 338/EC/FKRSDK/VI/2018. Analisis statistik menggunakan analisis bivariat (uji chi-square) dan multivariat (regresi logistik ganda). Tingkat signifikansi ditetapkan pada 0,05.

\section{Hasil Penelitian}

Tabel 1. Analisis bivariat pada kelompok kasus dan kontrol

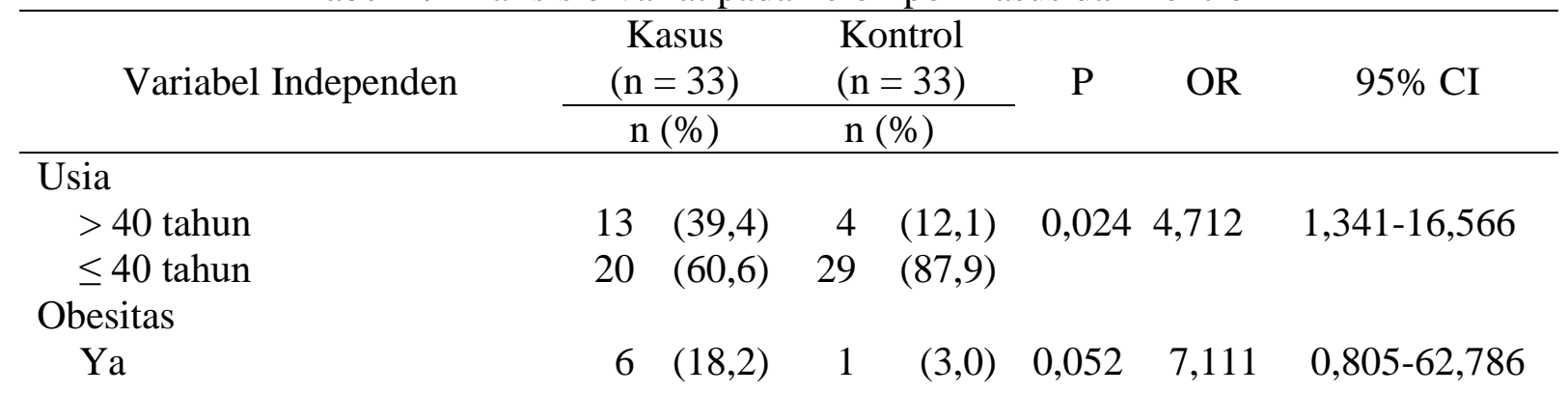


Tidak

Anemia

Ya

Tidak

Kebiasaan merokok

Ya

Tidak

Kebiasaan konsumsi alkohol

Ya

Tidak

Riwayat hilang kesadaran

selama menyelam

$$
\text { Ya }
$$

Tidak

Frekuensi riwayat penyakit dekompresi

$>1$ kali

1 kali

Riwayat penyakit komorbid hipertensi

$$
\text { Ya }
$$

Tidak

Riwayat penyakit komorbid diabetes mellitus

$$
\text { Ya }
$$

Tidak

Riwayat penyakit komorbid jantung Ya

Tidak

Riwayat penyakit komorbid sesak nafas

$$
\text { Ya }
$$

Tidak

Kedalaman menyelam

$$
\geq 30 \text { meter }
$$

$<30$ meter

Lama menyelam

$$
\geq 2 \text { jam }
$$$$
<2 \text { jam }
$$

Menyelam berulang dalam hari yang sama

$$
\text { Ya }
$$$$
\text { Tidak }
$$

$27 \quad(81,8) \quad 32 \quad(97,0)$

$\begin{array}{lllllll}23 & (69,7) & 9 & (27,3) & 0,001 & 6,133 & 2,111-17,824\end{array}$

$10 \quad(30,3) \quad 24 \quad(72,7)$

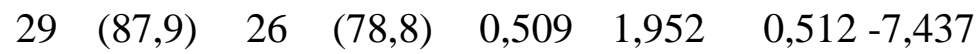

$4 \quad(12,1) \quad 7 \quad(21,2)$

$20 \quad(60,6) \quad 15 \quad(45,5) \quad 0,324 \quad 1,846 \quad 0,694-4,911$

$13 \quad(39,4) \quad 18 \quad(54,5)$

$18 \quad(54,5) \quad 3 \quad(9,1) \quad 0,000 \quad 12,00 \quad 3,048-47,244$

$15 \quad(45,5) \quad 30 \quad(90,9)$

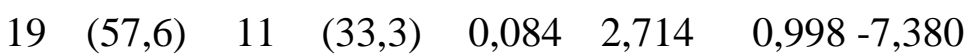

$14 \quad(42,4) \quad 22 \quad(66,7)$

$12 \quad(36,4) \quad 2 \quad(6,1) \quad 0,007 \quad 8,857 \quad 1,795-43,701$

$21 \quad(63,6) \quad 31 \quad(93,9)$

$\begin{array}{rrrrrrr}2 & (6,1) & 1 & (3,0) & 0,500 & 2,065 & 0,178-23,942 \\ 31 & (93,9) & 32 & (97,0) & & & \end{array}$

$\begin{array}{lllllll}1 & (3,0) & 1 & (3,0) & 0,754 & 1,000 & 0,060-16,690\end{array}$

$32(97,0) \quad 32 \quad(97,0)$

$\begin{array}{lllllll}7 & (21,2) & 4 & (12,1) & 0,509 & 1,952 & 0,512-7,437\end{array}$

$26 \quad(78,8) \quad 29 \quad(87,9)$

$\begin{array}{lllllll}29 & (87,9) & 15 & (45,5) & 0,001 & 8,700 & 2,493-30,364\end{array}$

$4 \quad(12,1) \quad 18 \quad(54,5)$

$\begin{array}{lllllll}21 & (63,6) & 13 & (39,4) & 0,085 & 2,692 & 0,995-7,284\end{array}$

$12(36,4) \quad 20 \quad(60,6)$ 
Tabel 2. Hasil analisis multivariat bermakna secara statistik

\begin{tabular}{clcccc}
\hline No. & \multicolumn{1}{c}{ Variabel Independen } & $\mathrm{B}$ & $\mathrm{P}$ & $\mathrm{OR}$ & $95 \%$ CI \\
\hline 1. & $\begin{array}{l}\text { Ada riwayat penyakit komorbid } \\
\text { hipertensi }\end{array}$ & 4,182 & 0,010 & 65,476 & $2,735-1.568$ \\
2. & Kedalaman menyelam $\geq 30$ meter & 3,648 & 0,014 & 38,410 & $2,114-698,028$ \\
3. & $\begin{array}{l}\text { Ada riwayat hilang kesadaran } \\
\text { selama menyelam }\end{array}$ & 2,522 & 0,009 & 12,456 & $1,884-82,363$ \\
4. & Lama menyelam $\geq 2$ jam & 2,289 & 0,021 & 9,860 & $1,410-68,943$ \\
5. & Menderita anemia & 2,179 & 0,024 & 8,837 & $1,332-58,632$ \\
6. & $\begin{array}{l}\text { Frekuensi riwayat penyakit } \\
\text { dekompresi }>1 \text { kali }\end{array}$ & 2,179 & 0,020 & 8,834 & $1,404-55,584$ \\
& & & & \\
\hline
\end{tabular}

Berdasarkan Tabel 2, ada riwayat penyakit komorbid hipertensi, kedalaman menyelam $\geq 30$ meter, ada riwayat hilang kesadaran selama menyelam, lama menyelam $\geq 2$ jam, menderita anemia, frekuensi riwayat penyakit dekompresi $>1$ kali secara statistik layak untuk dipertahankan dalam model.

Persamaan regresi logistik:

$\mathrm{y}=\alpha+\beta_{1} \mathrm{x}_{1}+\beta_{2} \mathrm{x}_{2}+\beta_{3} \mathrm{x}_{3}+\beta_{4} \mathrm{x}_{4}+\beta_{5} \mathrm{x}_{5}$ $+\beta_{6} \mathrm{X}_{6}$

$y=-7,629+(4,182 x$ ada riwayat penyakit komorbid hipertensi $)+(3,648 \mathrm{x}$ kedalaman menyelam $\geq 30$ meter) + $(2,522 \mathrm{x}$ ada riwayat hilang kesadaran selama menyelam $)+(2,289 \times$ lama menyelam $\geq 2$ jam $)+(2,179 x$ menderita anemia $)+(2,179 \mathrm{x}$ frekuensi riwayat penyakit dekompresi $>1$ kali).

$\mathrm{y}=-7,629+(4,182 \times 1)+(3,648 \times 1)+$ $(2,522 \times 1)+(2,289 \times 1)+(2,179 \times 1)$ $+(2,179 \times 1)$

$\mathrm{y}=9,370$

Probabilitas kejadian kualitas hidup buruk dapat dihitung dengan persamaan:

$$
\begin{aligned}
& \mathrm{P}=\frac{1}{1+\exp (-y)} \times 100 \% \\
& \mathrm{P}=\frac{1}{1+\exp (-9,370)} \times 100 \%=99 \%
\end{aligned}
$$

\section{Pembahasan}

Hasil analisis multivariat, variabel yang terbukti berpengaruh terhadap kualitas hidup penyelam tradisional penderita penyakit dekompresi adalah ada riwayat penyakit komorbid hipertensi $(\mathrm{p}=$ 0,010; $\mathrm{OR}=65,476)$, kedalaman menyelam $\geq 30$ meter $(\mathrm{p}=0,014 ; \mathrm{OR}=38,410)$, ada riwayat hilang kesadaran selama menyelam $(\mathrm{p}=0,009 ; \mathrm{OR}=12,456)$, lama menyelam $\geq$ 2 jam $(\mathrm{p}=0,021$; OR $=9,860)$, menderita anemia ( $\mathrm{p}=0,024$; OR $=8,837)$, frekuensi riwayat penyakit dekompresi $>1$ kali $(\mathrm{p}=$ 0,$020 ;$ OR $=8,834$ ), dengan probabilitas untuk terjadi kualitas hidup buruk sebesar $99 \%$.

Adanya riwayat penyakit komorbid hipertensi terbukti berpengaruh terhadap kualitas hidup buruk penyelam tradisional penderita penyakit dekompresi, saat dilakukan analisis multivariat hasilnya bermakna secara statistik ( $\mathrm{p}=0,010$; OR = 65,476; $95 \% \mathrm{CI}=2,735-1,568)$, dengan demikian adanya riwayat penyakit komorbid hipertensi mempunyai besar risiko 65,476 kali lebih besar untuk terjadi kualitas hidup buruk dibandingkan dengan yang tanpa riwayat penyakit komorbid hipertensi. Penggunaan obat diuretik pada 
penyelam penderita hipertensi menyebabkan ketidakseimbangan cairan dan garam dalam darah serta urinasi berlebih sehingga terjadi dehidrasi. ${ }^{18}$

Dehidrasi dapat mengubah removal gas inert dengan mengurangi aliran darah ke jaringan perfusi buruk, atau dapat menurunkan tegangan permukaan dengan demikian memfasilitasi pembentukan gelembung dan meningkatkan risiko terjadinya penyakit dekompresi. ${ }^{18,19}$ Selaras dengan penelitian yang dilakukan oleh Doolette et al. ${ }^{14}$ menyatakan bahwa peningkatan risiko penyakit dekompresi akan menurunkan status kesehatan penyelam sehingga kualitas hidupnya menurun. ${ }^{14}$

Kedalaman menyelam $\geq 30$ meter terbukti menjadi faktor yang berpengaruh terhadap kualitas hidup buruk penyelam tradisionl penderita penyakit dekompresi, saat dilakukan analisis multivariat hasilnya bermakna secara statistik ( $\mathrm{p}=0,014$; OR = $38,410 ; 95 \% \mathrm{CI}=2,114-698,028)$, dengan demikian menyelam dengan kedalaman $\geq$ 30 meter memiliki besar risiko 38,41 kali lebih besar untuk terjadi kualitas hidup buruk dibandingkan dengan yang menyelam dengan kedalaman $<30$ meter. Hasil ini selaras dengan penelitian yang menunjukkan bahwa kedalaman menyelam $\geq 30$ meter merupakan faktor risiko terhadap kejadian penyakit dekompresi dengan $\mathrm{OR}=6,622 .{ }^{20}$

Seorang penyelam semakin dalam menyelam maka semakin besar tekanan atmosfir yang diterima, dengan bertambahnya kedalaman menyelam risiko terjadi penyakit dekompresi semakin besar. ${ }^{21}$ Dengan bertambahnya kedalaman, kemungkinan terkena penyakit dekompresi semakin besar karena kelarutan gas dalam cairan tubuh semakin tinggi, sehingga bila penyelam naik ke permukaan dengan cepat, gas yang larut dalam cairan tubuh akan mengembang dengan cepat membentuk gelembung gas nitrogen yang akan menyebabkan penyumbatan, kerusakan jaringan $/ \mathrm{sel}^{22}$ Peningkatan risiko terjadi penyakit dekompresi akan menurunkan status kesehatan yang selanjutnya kualitas hidup akan menurun. ${ }^{14}$ Studi yang dilakukan Irgens et al. ${ }^{15}$ menyatakan menyelam pada kedalaman maksimal dihubungkan dengan penurunan kualitas hidup terkait kesehatan (HRQL) penyelam penderita dekompresi neurologis. Pada skala kualitas hidup, menyelam pada kedalaman maksimal dihubungkan dengan penurunan skor kualitas hidup pada skala nyeri tubuh, persepsi kesehatan secara umum, vitalitas, fungsi sosial, keterbatasan peran karena masalah emosional, dan kesehatan psikis. ${ }^{15}$

$$
\text { Hasil analisis multivariat }
$$
menunjukkan bahwa adanya riwayat hilang kesadaran selama menyelam terbukti berpengaruh terhadap kualitas hidup buruk penyelam tradisional penderita penyakit dekompresi $(\mathrm{p}=0,009 ; \mathrm{OR}=12,456 ; 95 \%$ $\mathrm{CI}=1,884-82,363)$, dengan demikian adanya riwayat hilang kesadaran selama menyelam memiliki besar risiko 12,456 kali lebih besar untuk terjadi kualitas hidup buruk dibandingkan dengan yang tidak ada riwayat hilang kesadaran. Hasil ini selaras dengan penelitian Sundal et $a ._{.}{ }^{23}$ dalam studinya menyatakan mantan penyelam dengan riwayat hilang kesadaran (loss of consciousness) memiliki skor kualitas hidup terkait kesehatan (HRQL) yang lebih rendah.

Penyelam yang mengalami pemutusan pasokan gas untuk bernafas menunjukkan HRQL yang lebih rendah. ${ }^{23}$ Begitu juga studi yang dilakukan Irgens et $a l .{ }^{24}$ menyatakan riwayat hilang kesadaran menunjukkan skor komponen fisik dan mental HRQL yang lebih rendah. ${ }^{24}$ Kehilangan kesadaran selama menyelam dapat terjadi karena banyak sebab. Keadaan lingkungan, peralatan selam, teknik penyelaman, dan kondisi kesehatan penyelam bisa menyebabkan penyelam 
kehilangan kesadaran. ${ }^{25}$ Hilang kesadaran pada penyelam paling sering disebabkan oleh terputusnya pasokan gas pernafasan, yang dihubungkan dengan hipoksia. ${ }^{23}$ Hipoksia dapat terjadi karena penyelam menahan nafas dalam waktu lama karena terputusnya pasokan gas pernafasan. ${ }^{25}$

Hilang kesadaran juga dapat disebabkan oleh paparan dingin air laut. Paparan dingin menyebabkan perubahan suhu penyelam selama penyelaman. Jika serapan nitrogen terjadi ketika suhu tubuh penyelam hangat dan aliran darah ke perifer baik, serta eliminasi nitrogen terjadi ketika suhu tubuh penyelam dingin dan aliran darah perifer berkurang, maka eliminasi nitrogen akan menjadi lebih lambat daripada serapan nitrogen, sehingga dapat meningkatkan jumlah gelembung gas nitrogen dalam aliran darah. ${ }^{21}$ Ketika gelembung gas nitrogen terjebak dalam aliran darah otak, akan menyebabkan hilang kesadaran dan timbul penyakit dekompresi. ${ }^{26}$ Peningkatan risiko penyakit dekompresi akan menurunkan status kesehatan penyelam sehingga kualitas hidupnya menurun. ${ }^{14}$

Lama menyelam terbukti menjadi faktor yang berpengaruh terhadap kualitas hidup buruk peyelam tradisional penderita penyakit dekompresi, saat dilakukan analisis multivariat menunjukkan hasil yang bermakna secara statistik ( $\mathrm{p}=0,021$; $\mathrm{OR}=9,860 ; 95 \% \mathrm{CI}=1,410-68,943)$. Dengan demikian lama menyelam $\geq 2$ jam memiliki besar risiko 9,86 kali lebih besar untuk terjadi kualitas hidup buruk dibandingkan dengan lama menyelam $<2$ jam. Hal ini selaras dengan penelitian yang menunjukkan bahwa lama menyelam $\geq 2$ jam merupakan faktor risiko kejadian penyakit dekompresi dengan OR = $61,680,{ }^{20}$ dimana peningkatan risiko terjadi penyakit dekompresi akan menurunkan kualitas hidup. ${ }^{14}$ Semakin lama waktu yang dibutuhkan untuk menyelam, semakin banyak jumlah nitrogen yang terakumulasi dalam jaringan. ${ }^{22}$ Lama waktu menyelam berpengaruh pada penyerapan dan pelepasan gas nitrogen dalam jaringan cepat dan jaringan lambat. Pembebanan nitrogen yang tinggi akan menyebabkan terjadinya penyakit dekompresi. ${ }^{25}$

Hasil analisis multivariat menunjukkan bahwa menderita anemia terbukti sebagai faktor yang berpengaruh terhadap kualitas hidup buruk penyelam tradisional penderita penyakit dekompresi $(\mathrm{p}=0,024 ; \mathrm{OR}=8,837 ; 95 \% \mathrm{CI}=1,332-$ 58,632), dengan demikian menderita anemia memiliki besar risiko 8,837 kali lebih besar untuk terjadi kualitas hidup buruk dibandingkan dengan yang tidak menderita anemia. Hal ini selaras dengan penelitian Duke et al. $^{20}$ yang menyatakan bahwa anemia merupakan faktor risiko terjadinya penyakit dekompresi $(\mathrm{p}=0,006$; $\mathrm{OR}=14,453),{ }^{20}$ dimana peningkatan risiko terjadinya penyakit dekompresi akan menurunkan status kesehatan penyelam yang mengakibatkan kualitas hidup menurun. ${ }^{14}$

Anemia menyebabkan kapasitas hemoglobin untuk membawa oksigen berkurang, akibatnya transportasi sel darah merah di dalam tubuh akan terganggu, jaringan tubuh akan kekurangan oksigen guna menghasilkan energi yang dapat mempengaruhi kebugaran fisik. Efek klinis anemia meliputi kelelahan, kelesuan, kelemahan, pucat, kemungkinan demam dan tekanan darah rendah. ${ }^{27}$

Hasil analisis multivariat menunjukkan bahwa frekuensi riwayat penyakit dekompresi > 1 kali terbukti menjadi faktor yang berpengaruh terhadap kualitas hidup buruk ( $\mathrm{p}=0,020 ; \mathrm{OR}=8,834 ; 95 \% \mathrm{CI}=$ 1,404 - 55,584), dengan demikian adanya frekuensi riwayat penyakit dekompresi $>1$ kali memilikii besar risiko 8,834 kali lebih besar untuk terjadi kualitas hidup buruk dibandingkan dengan yang frekuensi riwayat penyakit dekompresi 1 kali. Hasil ini selaras dengan penelitian yang 
dilakukan oleh Macdiarmid et al. ${ }^{1}$ menyatakan riwayat menderita penyakit dekompresi neurologis menunjukkan skor komponen mental kualitas hidup terkait kesehatan (HRQL) lebih rendah. ${ }^{1}$ Studi yang dilakukan oleh Irgens et $a l^{15}$ menyatakan mantan penyelam dengan riwayat pernah terserang dekompresi dilaporkan memiliki skor kualitas hidup yang lebih rendah pada semua skala SF-36 dibandingkan dengan mantan penyelam tanpa riwayat dekompresi. ${ }^{15}$ Studi yang dilakukan oleh Irgens et al. $^{24}$ menyatakan mempunyai riwayat penyakit dekompresi menunjukkan skor komponen fisik dan mental HRQL yang lebih rendah. ${ }^{24}$ Begitu juga studi yang dilakukan Bast-Pettersen et $a l .{ }^{28}$ menyatakan penyelam dengan riwayat penyakit dekompresi menunjukkan hasil tes memori yang buruk dan melaporkan lebih banyak gejala neuropsikiatrik. ${ }^{28}$

Penyelam yang sebelumnya mempunyai riwayat menderita penyakit dekompresi, memiliki risiko untuk terkena penyakit dekompresi kembali karena kemampuan tubuh untuk mengimbangi formasi gelembung berikutnya menjadi berkurang. ${ }^{21}$ Dengan meningkatnya risiko untuk terkena penyakit dekompresi kembali, akan menurunkan status kesehatan penyelam serta kualitas hidupnya. ${ }^{14}$

\section{Kesimpulan}

Berbagai faktor yang terbukti berpengaruh terhadap kualitas hidup penyelam tradisional penderita penyakit dekompresi adalah ada riwayat penyakit komorbid hipertensi, kedalaman menyelam $\geq 30$ meter, ada riwayat hilang kesadaran selama menyelam, lama menyelam $\geq 2$ jam, menderita anemia, frekuensi riwayat penyakit dekompresi >1 kali. Bila seseorang mempunyai karakteristik tersebut, probabilitas untuk terjadi kualitas hidup buruk adalah 99,99\%. Berbagai faktor yang tidak terbukti berpengaruh adalah usia > 40 tahun, obesitas, kebiasaan merokok, kebiasaan konsumsi alkohol, menyelam berulang dalam hari yang sama, ada penyakit komorbid diabetes mellitus, ada penyakit komorbid jantung, dan ada penyakit komorbid sesak nafas. Hasil

Focus Group Discussion (FGD) memberikan dukungan hasil penelitian kuantitatif bahwa responden yang mempunyai karakteristik berbagai faktor yang terbukti mempengaruhi kualitas hidup penyelam tradisional penderita penyakit dekompresi, sering mengeluh pusing, nyeri-nyeri pada tubuh terutama kaki dan persendian, lemah, lesu, timbul emosi yang mempengaruhi penyelam dalam melakukan aktivitas/pekerjaan sehari-hari baik secara fisik maupun mental.

\section{Ucapan Terimakasih}

Terimakasih kepada penyelam tradisional dengan penyakit dekompresi di Karimunjawa, Jawa Tengah yang bersedia menjadi obyek penelitian dan memberikan kontribusi dalam pengumpulan data.

\section{Daftar Pustaka}

1. Macdiarmid, J.I., Ross, J.A.S., Taylor, C.L., Watt, S.J., Adie, W., Osman, L.M., et al. 2005. Co-ordinated Investigation into The Possible Long Term Health Effects of Diving at Work. Examination of The Long Term Health Impact of Diving: The ELTHI Diving Study.

2. Vann, R.D., Butler, .FK., Mitchell, S.J., Moon, R.E. 2011. Decompression Illness. The Lancet;377(9760).pp.153164.

3. Commander NSSC. 2017. Manual US navy diving. Revision 7. US Navy.

4. Wahab, C., Budiningsih, S., Guritno, M. 2008. Decompression Sickness Among Moroami Diving Fishermen in 
Jakarta. Medical Journal of Indonesia; 17(3).pp.197.

5. McQueen, D., Kent, G., Murrison, A. 1994. Self-Reported Long-Term Effects of Diving and Decompression Illness in Recreational Scuba Divers. British Journal of Sports Medicine; 28(2).pp.101-104.

6. Kemenkes RI. 2013. Profil Pengendalian Penyakit dan Penyehatan Lingkungan Tahun 2012. Jakarta: Direktorat Jenderal Pengendalian Penyakit dan Penyehatan Lingkungan.

7. Laurens, E., Howle, P.W., Weber, Ethan, A., Hada, Richard, D., Vann, Denoble, P.J. 2017. The Probability and Severity of Decompression Sickness. PLoS ONE;12 (3).

8. Richard, H.J.D., Geoff, F., Bridget, D.C., Andrew, F., Andrea, J.B. 2015. A 10-Year Estimate of The Incidence of Decompression Illness in A Discrete Group of Recreational Cave Divers in Australia. Decompression Illness in Cave Divers.

9. Peter, G. 2006. The Medical Risks of Underwater Diving and Their Control. International Sport Med Journal; 7(1), pp.1-15.

10. Kemenkes RI. 2013. Riset Kesehatan Dasar 2013. Jakarta: Badan Penelitian dan Pengembangan Kesehatan Kementerian Kesehatan RI.

11. Kemenkes RI. 2013. Risiko Kesehatan Para Nelayan dalam Upaya Pemenuhan Kebutuhan. Jakarta.

12. Kartono, S.A. 2007. Prevalensi dan Faktor Risiko Kejadian Penyakit Dekompresi dan Barotrauma pada Nelayan Penyelam di Kecamatan Karimunjawa Kabupeten Jepara. Tesis. Yogyakarta: Fakultas Kedokteran, Universitas Gadjah Mada.

13. WHO. 1999. WHOQOL: Annotated Bibliography, October 1999 Version. Geneva Switzerland: WHO.
14. Doolette, DJ, Gorman, DF. 2003. Evaluation of Decompression Safety in An Occupational Diving Group Using Self Reported Diving Exposure and Health Status. Occupational and Environmental Medicine;60(6).pp. 418 -422 .

15. Irgens, A., Gronning, M., Troland, K., Sundal, E., Nyland, H., Thorsen, E. 2007. Reduced Health-Related Quality of Life in Former North Sea Divers is Associated With Decompression Sickness. Occupational Medicine; 57(5).pp.349-354.

16. Ware Jr, JE.2000. SF-36 health survey update. Spine; 25(24).pp.3130-3139.

17. Modersitzki, F., Pizzi, L., Grasso, M., Goldfarb, D.S. 2014. Health-Related Quality of Life (HRQoL) in Cystine Compared With Non-Cystine Stone Formers. Urolithiasis;42(1).pp.53-60.

18. Mitchell, S., Taylor, L. 2005. Diving and high blood pressure (hypertension):www.nzu.org.nz/wp.../ 08/NZUA-DivingHypertension.pdf;

19. Fahlman, A., Dromsky, D.M. 2006. Dehydration effects on the risk of severe decompression sickness in a swine model. Aviation, Space, and EnvironmentalMedicine;77(2).pp.102106.

20. Duke, H.I., Hadisaputro, S., Chasani, S. 2017. Pengaruh Kedalaman Menyelam, Lama Menyelam, Anemia terhadap Kejadian Penyakit Dekompresi pada Penyelam Tradisional. Jurnal Kesehatan Masyarakat Indonesia;12(2).pp.12.

21. Mitchell, S. 2005. Risk Factors for Decompression Illness. DAN SE Asia Pacific.

22. Mitchell, S. 2005. The Mechanisms of Decompression Illness Part 1. DAN SE Asia Pacific.

23. Sundal, E., Irgens, A., Troland, K., Thorsen, E., Gronning, M. 2013. Prevalence and Causes of Loss of 
Consciousness in Former North Sea Occupational Divers. International Maritime Health;64(3).pp.142-147.

24. Irgens, A., Troland, K., Djurhuus, R., Gronning, M. 2016. Diving Exposure and Health Effects in Divers Working in Different Areas of Professional Diving. International Maritime Health;67(4).pp.235-242.

25. LAKESLA. 2016. Ilmu Kesehatan Penyelaman dan Hiperbarik. Surabaya: Lembaga Kesehatan Kelautan TNI AL Drs. Med. R. Rijadi S., Phys.

26. Mitchell, S. 2005. The Mechanisms of Decompression llness Part 2. DAN SE Asia Pacific.
27. Campbell, ES. 2018. Overview of the Problem of Diving with Anemia 2002. Disitasi tanggal 9 Februari 2018. Available from: http://www.gulftel. $\mathrm{com} / \sim$ scubadoc/anem.html.

28. Bast-Pettersen, R., Skare, O, Nordby, K, Skogstad, M. 2015. A Twelve-Year Longitudinal Study of Neuropsychological Function in Non-Saturation Professional Divers. International Archives of Occupational and Environmental Health;88(6).pp.669-682. 